\title{
Importance of Lipid Peroxidation, Protective Enzymes and Trace Elements in Chronic Leg Ischaemia
}

\author{
Peter Ondruš $\check{1}^{1}$ Roman Alberty ${ }^{2}$ and Zuzana Vassanyiova ${ }^{2}$ \\ 1 Department of Surgery \\ 2 Department of Clinical Biochemistry \\ Roosevelt Hospital, Banská Bystrica, Slovak Republic
}

Summary: The aim of this study was to assess lipid peroxidation in chronic leg ischaemia by determining thiobarbituric acid reactants. Furthermore, $\mathrm{Cu}, \mathrm{Zn}$-superoxide dismutase and glutathione peroxidase activities as well as the trace element profile $(\mathrm{Zn}, \mathrm{Cu}, \mathrm{Se}, \mathrm{Mg}$ ) were determined. Fasting blood samples from the common femoral artery and vein were taken from both legs of 15 patients ( $57 \pm 7$ years) with peripheral arteriosclerosis and 9 individuals (54 \pm 9 years) of the control group without chronic leg ischaemia.

Patients with peripheral arteriosclerosis showed significantly decreased venous thiobarbituric acid reactant levels $(2.01 \pm 0.37$ vs $2.39 \pm 0.59 \mu \mathrm{mol} / 1$ in controls, $\mathrm{p}<0.05)$. Both arterial and venous samples from patients showed lower $\mathrm{Cu}, \mathrm{Zn}$-superoxide dismutase activities and higher glutathione peroxidase activities than controls. Venous activities of glutathione peroxidase were significantly higher than arterial activities in both groups (patients $0.52 \pm 0.18$ vs $0.43 \pm 0.15 \mu \mathrm{kat} / \mathrm{g} \mathrm{Hb}, \mathrm{p}<0.001$, control group $0.51 \pm 0.12$ vs $0.39 \pm 0.19 \mu \mathrm{kat} / \mathrm{g} \mathrm{Hb}, \mathrm{p}<0.01)$. The trace element profile of the patients showed a highly significant decrease in magnesium levels $(p<0.001)$ and increased venous copper levels $(p<0.05)$. No significant changes were found in zinc and selenium levels. The results of this study show that during chronic leg ischaemia the production of free oxygen radicals at rest is well controlled, but the activity of antioxidant enzymes seems to be impaired.

\section{Introduction}

Lipid peroxidation, i.e. alteration of polyunsaturated fatty acids by free oxygen radicals, plays an important role in the pathogenesis of many diseases including atherosclerosis. Oxidatively modified low density lipoproteins (LDL) play an important role in the development of atherosclerosis. Subendothelial oxidized LDL undergoes accelerated endocytosis by macrophages via their scavenger receptors, leading to cholesterol accumulation $(1,2)$. For laboratory investigation, the determination of thiobarbituric acid reactants is widely used for evaluating overall lipid peroxidation (3).

The antioxidant potential of blood is normally sufficient to counteract the local tissue generation of free oxygen radicals. However, in atherosclerotic diseases the activity of antioxidant enzymes and the microelement status, which are implicated in protection against free oxygen radicals, are significantly modified $(4,5)$.

The majority of research has been concentrated on acute ischaemic/reperfusion injury of myocardium, and only a few studies have been reported on patients with chronic leg ischaemia (6-8). Therefore, the aim of the present study was to investigate a possible role of lipid peroxidation and some antioxidant protective mechanisms in chronic leg ischaemia in patients with angiographically verified peripheral arterial occlusive disease.

The amount of lipid peroxidation was assessed by thiobarbituric acid reactant concentration. We also evaluated the importance of $\mathrm{Cu}, \mathrm{Zn}$-superoxide dismutase ${ }^{1}$ ) and glutathione peroxidase ${ }^{l}$ ) activities as well as serum levels of zinc, copper, selenium and magnesium as possible effectors in protection against, or acceleration of, the arteriosclerotic process. The analytes were determined in blood samples from the common femoral artery and vein, in order to evaluate local metabolic changes in chronic leg ischaemia at rest.

\section{Materials and Methods}

\section{Patients}

The study included 15 patients from the Department of Surgery, Roosevelt Hospital (10 men and 5 women) with a mean age of $57 \pm 7$ years (mean $\pm \mathrm{SD}$ ); a total of 30 lower limbs were examined. In view of the nature of the experiment, each patient's lower

\footnotetext{
1) Enzymes:

Glutathione peroxidase, glutathione : hydrogen-peroxide oxidoreductase, EC 1.11.1.9)

Superoxide dismutase (superoxide : superoxide oxidoreductase, EC 1.15.1.1)

Xanthine oxidase (xanthine : oxygen oxidoreductase, EC 1.1.3.22)
} 
extremity was regarded as a separate clinical entity. Obliterative arteriosclerosis of the lower limb was verified by angiography. All patients showed diffuse arteriosclerotic lesions, predominantly in the femoropopliteal segment. Ten lower limbs were considered as critical lcg ischaemia. patients with gangrene or diabetes mellitus were excluded from the study. The patients had been receiving an oral haemorheologic preparation since long before the present investigation. Eleven patients $(73 \%)$ were regular smokers at the time of the study.

\section{Control group}

A control group was made up of 9 individuals $(6$ men and 3 women) from the Department of Neurosurgery, Roosevelt Hospital, who had undergone angiographic examinations for other reasons. The mean age of the control group was $54 \pm 9$ years (mean \pm SD) and a total of 18 lower limbs were examined. Peripheral arterial occlusive disease and diabetes mellitus were absent in this group according to clinical and laboratory investigations.

The study was approved by the local Ethics Committee and written informed consent was obtained.

\section{Blood sampling and sample preparation}

Fasting blood samples were collected from supine patients, first from the common femoral vein and immediately thereafter from the common femoral artery. The patients remained in the supine position at rest for 30 minutes before examination. Samples in the control group were taken before the angiographic examination under the same conditions. Blood was collected into $2.7 \mathrm{ml}$ heparinised and $2.7 \mathrm{ml}$ serum preparation tubes, both trace element-free (Sarstedt Monovette, Nümbrecht, Germany). About $2 \mathrm{ml}$ of heparinised whole blood was used immediately for the enzyme determination. The remainder of the blood was then centrifuged $(2000 \mathrm{~g}$ for $10 \mathrm{~min}$ at $20^{\circ} \mathrm{C}$ ), and plasma or serum were removed carefully to avoid platelets and exogenous contamination. The samples for thiobarbituric acid reactants and trace element determination were analysed either immediately on the same day or stored frozen at $-20^{\circ} \mathrm{C}$ in Eppendorf polypropylene micro test tubes (Hamburg, Germany) and analysed later within 5 days.

\section{Samples Analysis}

\section{Thiobarbituric acid reactants}

Thiobarbituric acid reactants were determined in plasma with a modified fluorometric thiobarbituric acid test (9). Briefly, the plasma sample was heated $\left(60\right.$ minutes at $\left.90^{\circ} \mathrm{C}\right)$ at low $\mathrm{pH}$ with thiobarbituric acid. After cooling in tap water, $2 \mathrm{ml}$ of $n$-butanol was added. The thiobarbituric acid reactant complex was extracted by shaking, the phases separated by centrifugation and the $n$-butanol layer was taken for fluorometric measurement (excitation $\lambda=515 \mathrm{~nm}$ and emission $\lambda=553 \mathrm{~nm}$ ) using a fluorescence spectrophotometer, model 204 (Perkin Elmer Ltd., Norwalk, USA). The thiobarbituric acid reactant concentration was derived from a standard of 1,1,3,3-tetramethoxypropane. Results are expressed in $\mu \mathrm{mol} / 1$. For plasma thiobarbituric acid reactant concentration $<2.5$ $\mu \mathrm{mol} / 1$ the intra- and inter-assay $\mathrm{CVs}$ were $2.9 \%$ and $4.4 \%$, respectively. For all analytes in this study, intra- and inter-assay variations were estimated from replicate analysis in 10 different analytical runs, using the due order one-stage ANOVA model (10). Accuracy was measured by evaluating the analytical recovery of our manual standard additions. Analytical recovery was $86-102 \%$ (mean $96 \%$, $n=8$ ) when the final concentration of thiobarbituric acid reactants was $<4 \mu \mathrm{mol} / \mathrm{l}$.

\section{Enzyme analysis}

$\mathrm{Cu}, \mathrm{Zn}$-superoxide dismutase activity was determined with Ransod, a superoxide dismutase kit, based on the capacity of $\mathrm{Cu}, \mathrm{Zn}$-superoxide dismutase to inhibit the reduction of phenyltetrazolium chloride by xanthine oxidase. Glutathione peroxidase activity was measured with Ransel, a glutathione peroxidase kit (both from Randox Lab, Crumlin, N. Ireland) based on the modified method of Pag- lia \& Valentine (11) using cumene hydroperoxide as a substrate. $\mathrm{Cu}, \mathrm{Zn}$-superoxide dismutase and glutathione peroxidase assays were performed on a Cobas Mira (Hoffmann-La Roche, Basle, Switzerland), an automated chemistry analyser with intra- and inter-assay precisions $(\mathrm{CVs})<2.9 \%$ and $<4.2 \%$, respectively. Activities of both enzymes are expressed in $\mu \mathrm{kat} / \mathrm{g}$ of haemoglobin of whole blood. Haemoglobin concentration was determined with a haemoglobin kit (Lachema, Brno, Czech Republic) using the cyanomethaemoglobin method.

\section{Trace element analysis}

Serum zinc and magnesium concentrations were determined by flame atomic absorption using Varian Spectr AA-30 with a deuterium background correction. Copper and selenium concentrations were determined with a graphite furnace technique using GTA-95 with autosample dispenser (both from Varian Techtron, Mulgrave, Australia). For all elements except Se, the intra- and inter-assay CVs were $<4.2 \%$ and $<5.9 \%$, respectively. Selenium intra- and inter-assay variations were (CVs) $<6.3 \%$ and $<9.2 \%$, respectively. Accuracy for $\mathrm{Zn}, \mathrm{Mg}$ and $\mathrm{Cu}$ determinations was verified by analysing the human control serum Qualitrol HSN (Merck, Darmstadt, Germany). Analytical bias found for $\mathrm{Zn}$ and $\mathrm{Mg}$ was $<3.8 \%$ and for copper $<5.2 \%$. Recoveries of added Se were $92-$ $106 \%$ (mean $97 \%, \mathrm{n}=8$ ) when the final concentrations were $<1.6 \mu \mathrm{mol} / \mathrm{l}$.

\section{Reagents and standards}

2-Thiobarbituric acid $99 \%$ and sulphuric acid $95-97 \%$ p. a. were obtained from Merck, Darmstadt, Germany. 1,1,3,3-Tetramethoxypropane $98 \%$ was from Aldrich Chemical Co., Milwaukee, USA. $n$-Butanol $99 \%$ and atomic absorption standard solutions for zinc, copper, magnesium and selenium were purchased from Sigma Chemical Co, St. Louis, USA.

\section{Statistical analysis}

Student's t-test for paired and unpaired samples and simple linear regression analysis were used for statistical evaluation of the results. Differences were considered as significant at the $p<0.05$ level.

\section{Results}

Results of biochemical analysis of arterial and venous blood samples obtained from patients with chronic leg ischaemia and from the control group are given in table 1.

Patients with peripheral arterioslcerosis showed significantly decreased venous thiobarbituric acid reactant concentrations $(2.01 \pm 0.37$ vs $2.39 \pm 0.59 \mu \mathrm{mol} / 1$ in controls, $p<0.05$ ). Both arterial and venous samples from patients had lower $\mathrm{Cu}, \mathrm{Zn}$-superoxide dismutase activities and higher glutathione peroxidase activities than controls. Venous activities of glutathione peroxidase were significantly higher than arterial activities in both groups (patients $0.52 \pm 0.18$ vs $0.43 \pm 0.15 \mu \mathrm{kat} / \mathrm{g} \mathrm{Hb}$, $\mathrm{p}<0.001$, control group $0.51 \pm 0.12$ vs $0.39 \pm 0.19$ $\mu \mathrm{kat} / \mathrm{g} \mathrm{Hb}, \mathrm{p}<0.01$ ). The trace element profile of the patients showed a highly significant decrease in magnesium levels $(p<0.001)$ and increased venous copper levels $(p<0.05)$. No significant changes were found in zinc and selenium levels. Results from simple linear regression analysis are shown in table 2. Magnesium levels in the control group showed significant correlations with the levels of $\mathrm{Cu}, \mathrm{Zn}$-superoxide dismutase 
(artery $r=-0.839, p<0.001$, vein $r=-0.739$, $\mathrm{p}<0.01$ ), glutathione peroxidase (artery $\mathrm{r}=0.623$, $\mathrm{p}<0.05$ ), $\mathrm{Zn}$ (artery $\mathrm{r}=0.788, \mathrm{p}<0.001$, vein $\mathrm{r}=0.549, \mathrm{p}<0.01$ ) and $\mathrm{Cu}$ (artery $\mathrm{r}=0.765$, $p<0.001$, vein $r=0.572, p<0.05$ ). In contrast, these correlations were not observed in patients.

\section{Discussion}

Chronic leg ischaemia constitutes, for tissues, a combination of inadequate supply of substrates and oxygen with an insufficient efflux of toxic products.

In healthy individuals, free oxygen radical production is controlled by antioxidative enzymes. As already reported by Manso for hypoxia (12), the venous blood levels of thiobarbituric acid reactants in our ischaemic patients were lower than in controls. The decrease in $\mathrm{pO}_{2}$ in venous blood may restrict the availability of oxygen for free oxygen radical production. However, the difference in thiobarbituric acid reactant concentrations between patients and controls was not as great as would be expected. Our results indicate that a certain amount of thiobarbituric acid reactants can be produced during oxygen deprivation. In the hypoxic status, free oxygen radicals may be generated within muscle cells and by the endothelial xanthine oxidase $(12,13)$.
The thiobarbituric acid test is used as the main assay for lipid peroxidation. In recent years this assay has been subjected to pervasive criticism on several grounds:

1) Thiobarbituric acid assay is based on the quantitative measurement of aldehyde breakdown products of some, but not all lipid hydroperoxides;

2) Because the thiobarbituric acid test is calibrated with malondialdehyde the results are often expressed in malondialdehyde content, although the terms "malondialdehyde-like material" or "thiobarbituric acid reactants" would be more appropriate;

3) In humans, only a small fraction of lipid peroxides can be converted into malondialdehyde and, more, malondialdehyde is formed during the thiobarbituric acid procedure from various non-lipid compounds including DNA, carbohydrates and amino acids;

4) The thiobarbituric acid test lacks specificity, and the assays show poor precision.

Accepting these limitations, however, rigorous control of this simple test procedure and careful interpretation of the results can yield useful information on lipid peroxide production. Recently, direct determination of malondialdehyde with the thiobarbituric acid/HPLC technique was recommended (14).

Tab. 1 Results of biochemical analysis of arterial and venous blood samples obtained from patients with chronic leg ischaemia and from the control group.

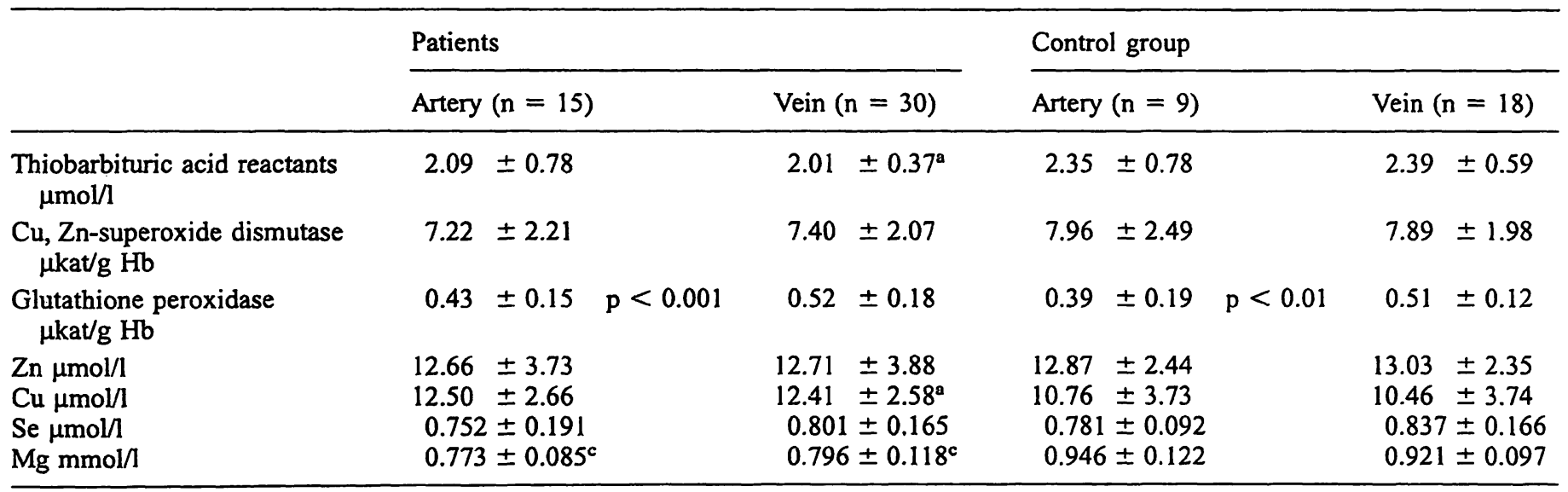

Values are means \pm SD. Statistically significant differences between patients with chronic leg ischaemia and the control group are ${ }^{\mathrm{a}} \mathrm{p}<0.05$ and ${ }^{\mathrm{c}} \mathrm{p}<0.001$.

Tab. 2 Results of simple linear regression for chosen quantities

\begin{tabular}{|c|c|c|}
\hline & Control group & Patients \\
\hline $\mathrm{Cu}, \mathrm{Zn}$-superoxide dismutase vs glutathione peroxidase & art $r=-0.734^{b}$ & $\begin{array}{l}\text { art } r=0.582^{b} \\
\text { vein } r=0.418^{b}\end{array}$ \\
\hline $\mathrm{Cu}, \mathrm{Zn}$-superoxide dismutase vs thiobarbituric acid reactants & - & art $r=0.489^{\mathrm{a}}$ \\
\hline Glutathione peroxidase vs thiobarbituric acid reactants & - & art $r=0.741^{c}$ \\
\hline $\mathrm{Cu}, \mathrm{Zn}$-superoxide dismutase vs $\mathrm{Cu}, \mathrm{Zn}$ & $\begin{array}{l}\mathrm{Cu} \text { art } r=-0.676^{\mathrm{b}} \\
\mathrm{Zn} \text { art } \mathrm{r}=-0.501^{\mathrm{a}}\end{array}$ & - \\
\hline Glutathione peroxidase vs Se & art $r=0.696^{b}$ & - \\
\hline
\end{tabular}

art $=$ artery, ${ }^{a} p<0.05,{ }^{b} p<0.01,{ }^{c} p<0.001$ 
Like Belch (7), we found a decrease in $\mathrm{Cu}, \mathrm{Zn}$-superoxide dismutase and an increase in glutathione peroxidase activities in patients. In the control group, $\mathrm{Cu}, \mathrm{Zn}$-superoxide dismutase was negatively correlated with glutathione peroxidase, suggesting a balanced state and indicating the capacity of the blood to eliminate free oxygen radicals. By contrast, patients showed a positive correlation between $\mathrm{Cu}, \mathrm{Zn}$-superoxide dismutase and glutathione peroxidase. This finding was supported by the correlation of arterial values of $\mathrm{Cu}, \mathrm{Zn}$-superoxide dismutase and glutathione peroxidase with thiobarbituric acid reactants in patients. $\mathrm{Cu}, \mathrm{Zn}$-superoxide dismutase can be seen as the first line defence against oxidative damage to membrane lipids, while glutathione peroxidase would form a second line of defence by detoxifying organic peroxides formed by the molecular species not inactivated by $\mathrm{Cu}, \mathrm{Zn}$-superoxide dismutase $(15,16)$. More glutathione peroxidase would thus be necessary when less $\mathrm{Cu}, \mathrm{Zn}$-superoxide dismutase is present, and vice versa. This could explain the negative correlation between $\mathrm{Cu}, \mathrm{Zn}$-superoxide dismutase and glutathione peroxidase observed in controls. These same arguments support the existence of mechanisms regulating the activities of $\mathrm{Cu}, \mathrm{Zn}$-superoxide dismutase and glutathione peroxidase according to need. The positive correlation of $\mathrm{Cu}, \mathrm{Zn}$-superoxide dismutase and glutathione peroxidase with thiobarbituric acid reactants in patients would indicate a long term adaptation mechanism to hypoxia.

The microelement profile in the serum of patients with peripheral arteriosclerosis is characterised by a low magnesium, low normal zinc and selenium concentrations, and an elevated concentration of copper (5). In health, the concentrations of most microelements in the serum decrease with age (17).

The Slovak population shows generally lower selenium levels (18). In our study, serum selenium values were also low. Similarly, the activity of glutathione peroxidase, a selenium dependent enzyme, was lower in both examined groups compared with the normal reference range of the manufacturer's kit $(0.52-0.78 \mu \mathrm{kat} / \mathrm{g} \mathrm{Hb}$ for whole blood). In the heart, selenium deficiency induces an accumulation of lipid peroxides especially under ischaemic conditions (19). However, we could not demonstrate this increase of the lipid peroxides in chronic leg ischaemia.

Increased lipid peroxidation may be a contributing factor in the pathophysiology of low copper status. In contrast, peripheral vascular disease results in increased ceruloplasmin and copper concentrations in serum (5, 20). Thus the higher serum copper levels, observed in our patients, do not stimulate the increase of lipid peroxide production.
Zinc and copper also control the free oxygen radical concentration via the Fenton reaction. Zinc deficiency may, in part, enhance lipid peroxidation in humans (21). In controls, the serum levels of $\mathrm{Cu}$ and $\mathrm{Zn}$ correlated negatively with whole blood levels of $\mathrm{Cu}, \mathrm{Zn}$-superoxide dismutase, a copper and zinc dependent enzyme. This finding was not observed in patients, indicating impairment of this antioxidant system.

Decreased Mg levels may be involved in lipid peroxidative process and are associated with atherosclerotic disease (17). Magnesium levels were significantly lower in patients than in controls. The correlations between $\mathrm{Mg}$ and all the monitored quantities confirm the important role played by $\mathrm{Mg}$ in metabolism. The balance, however, becomes upset in permanent tissue ischaemia.

We have postulated that arterio-venous differences reflect local metabolic changes. We assumed that the evaluation of metabolism at rest eliminates the influence of blood flow changes in the leg, so that the measured concentrations should reflect the amounts of metabolites actually produced. In our study, arterio-venous differences at rest did not mirror local changes in metabolism, as demonstrated during exercise or in an animal model (22, 23). In both groups, the arterial and venous values for most of the measured quantities were not significantly different. Only glutathione peroxidase showed a significant increase in venous blood in both groups. The fall of $\mathrm{pO}_{2}$ in the venous circulation may induce a transient increase of glutathione peroxidase activity as an antioxidant reserve before lung oxygen reabsorption. The transient increase of glutathione peroxidase activity in venous blood may also indicate the presence of a short term regulatory mechanism, or a cellular efflux of this enzyme.

In conclusion, the effect of ischaemia may differ in various parts of the body. The patients investigated showed an inhibition of lipid peroxide production and impairment of an antioxidant enzyme system. Other factors that may favour lipid peroxidation, such as an observed slight decrease in zinc and selenium serum levels, and in particular a significant decrease in magnesium levels, had no influence on lipid peroxide concentrations in our patients.

\section{Acknowledgements}

The authors thank Dr. I. Jerabková for help with statistical analysis, Dr. B. Preiss and Dr. J. Brault, Department of Clinical Biochemistry, Sherbrooke University Hospital for reviewing the work, Mrs S. Styková for technical help and Dr R. Prahl for assistance in preparation of the manuscript. 


\section{References}

1. Luc G, Fruchart J-Ch. Oxidation of lipoproteins and atherosclerosis. Am J Clin Nutr 1991; 53:206S-9S.

2. Schivartz CJ, Valentc AJ, Sprague EA. A modern view of atherogenesis. Am J Cardiol 1993; 71:9B-14B.

3. Esterbauer H, Schaur JR, Zollner H. Chemistry and biochemistry of 4-hydroxynonenal, malondialdehyde and related aldehydes. Free Radic Biol Med 1991; 11:81-128.

4. Locper J, Goy J, Rosensztajn OB, Moisson P. Lipid peroxidation and protective enzymes during myocardial infarction. Clin Chim Acta 1991; 196:119-26.

5. Iskra M, Patelski J, Majewski W. Concentrations of calcium, magnesium, zinc and copper in relation to free fatty acids and cholesterol in scrum of atherosclerotic men. $\mathrm{J}$ Trace Elem Electrolyte Health Dis 1993; 7:185-8.

6. Lau CS, Scott N, Shaw JW, Belch F. Increased activity of oxygen free radicals during reperfusion in patients with peripheral arterial disease undergoing perculaneous peripheral artery balloon angioplasty. Int Angiol 1991; 10:244-6.

7. Belch JJF, Chopra M, Hutchison S, Lorime R, Sturrock RD, Forbes $C D$, et al. Free radical pathology in chronic arterial disease. Free Radic Biol Med 1989; 6:375-8.

8. Holomán̆ M, Záhorec R, Kusý J, Pechán̆ l. Biochemical monitoring in patients during revascularization surgery. Vasa 1995; 24(1):23-8.

9. Schimke 1, Papies B. Einige methodische Aspekte der Bestimmung thiobarbitursäure-reaktiver Substanzen im Plasma. Z Med Lab Diagn 1986; 27(2):71-5.

10. Tietz NW, editor. Textbook of clinical chemistry. Philadelphia: Saunders, 1986

11. Paglia DA, Valentine WN. Studies on the quantitative and qualitative characterisation of erythrocyte glutathione peroxidase. J Lab Clin Med 1967; 70:758-69.

12. Manso C. Fundamentos da cardiologia clinica. A lesão de isquémia/reperfusão. Rev Port Cardiol 1994; 13(3):267-76.

13. Hess ML, Krause S, Kontos HA. Mediation of sarcoplasmic reticulum disruption in the ischaemic myocardium: proposed mechanism by the interaction of hydrogen ions and oxygenfree radicals. Adv Exp Med Biol 1982; 161(2):377-89.
14. Wong SHY, Knight JA, Hopfer SM, Zaharia O, Leach Jr CHN, Sunderman $\mathrm{Jr}$ FW. Lipoperoxides in plasma as measured by liquid-chromatographic separation of malondialdehyde-thiobarbituric acid adduct. Clin Chem 1987; 33(2):214-20.

15. Ferrari R, Ceconi C, Curello S, Cargnoni A, Alfieri O, Pardini $A$, et al. Oxygen free radicals and myocardial damage: protective role of thiol-containing agents. Am J Med 1991; 91(3c):95s-105s.

16. Chandra M, Chandra N, Agrawal R, Kumar A, Ghatak A, Pandey $V$. The free radical system in ischemic heart disease. Int $J$ Cardiol 1994; 43:121-5.

17. Günther T. Magnesium deficiency, oxygen radicals and aging. Magnes Bull 1991; 13(3):78-81.

18. Brtková $A$, Magálová T, Babinská $K$, Béderová $A$. Serum selenium levels in Slovak population. Biol Trace Elem Res 1994; 46:163-71.

19. Ytrehus K, Hegstad A-C. Lipid peroxidation and membrane damage of the heart. Acta Physiol Scand 1991; S599:81-91.

20. Salonen JT, Salonen R, Seppanen K, Kantola M, Suntioinen $S$, Korpela $H$. Interactions of serum copper, selenium, and low density lipoprotein cholesterol in atherogenesis. Brit Med $\mathrm{J}$ 1991; 302:756-60.

21. Wilking GM, Leake DS. The oxidation of low density lipoprotein by cells or iron is inhibited by zinc. FEBS Letters 1994;341:259-62.

22. Saxton JM, Donnelly AE, Roper HP. Indices of free-radicalmediated damage following maximum voluntary eccentric and concentric muscular work. Eur J Appl Physiol 1994; 68:189-93.

23. Reikeras $O$, Ytrehus $K$. Oxygen radicals and scavenger enzymes in ischaemia-reperfusion injury of skeletal muscle. Scand J Clin Lab Invest 1992; 52:113-8.

Received November 20, 1995/March 6, 1996

Corresponding author: RNDr. Roman Alberty, CSc, Oddelenie klinickej biochémie, Rooseveltova nemocnica, SR-97517 Banská Bystrica, Slovak Republic 
